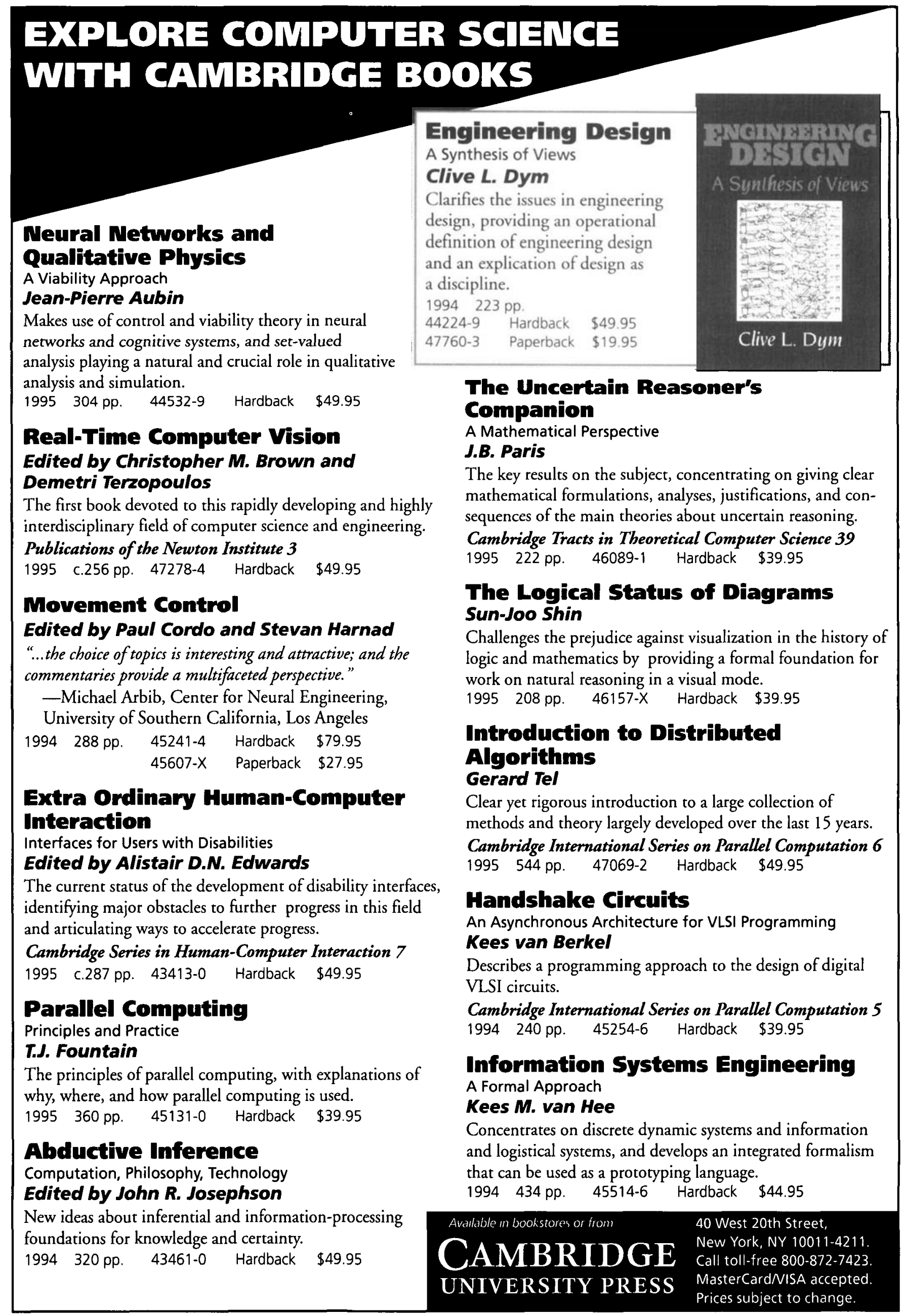




\section{$\Delta \prod^{2}$ DAMMM}

INSTRUCTIONS FOR AUTHORS

\begin{abstract}
AIMS AND SCOPE
AI EDAM: Artificial Intelligence for Engineering Design, Analysis and Manufacturing is an archival research journal that is intended to reach two audiences: engineers and designers who see Al technologies as powerful means for solving difficult engineering problems; and researchers in $A I$ and computer science who are interested in applications of $\mathrm{Al}$ and in the theoretical issues that arise from such applications. The Editor is specifically seeking original articles that develop new and interesting applications based on the most up-to-date research in all branches and phases of engineering, including analysis, synthesis and design; manufacturing and assembly; and concurrent engineering. The journal is interested in the use of AI in planning, design, analysis, simulation, spatial reasoning and graphics, manufacturing, assembly, process planning, scheduling, numerical analysis, and optimization. Areas of special interest include: knowledge-based (expert) systems for engineering, including knowledge acquisition and representation, control, and system architectures; theoretical work on the modeling of engineering problem-solving and design processes; the integration of $\mathrm{Al}$-based techniques with numerical analysis tools, graphics and solid modeling packages, and engineering databases; and engineering applications of knowledge-based vision and of natural language processing.
\end{abstract}

\section{ORIGINALITY AND COPYRIGHT}

To be considered for publication in $A / E D A M$ a manuscript cannot have been published previously, nor can it be under review for publication elsewhere. Papers with multiple authors are reviewed with the assumption that all authors have approved the submitted manuscript and concur in its submission to AI EDAM. A Transfer of Copyright Agreement must be executed before an article can be published. Government authors whose articles were created in the course of their employment must so certify in lieu of copyright transfer. Authors are responsible for obtaining written permission from the copyright owners to reprint any previously published material included in their article.

\section{MANUSCRIPT SUBMISSION AND REVIEW}

Three high quality copies of articles, in English, should be submitted to the Editor.

Professor Clive L. Dym, Editor

\section{AI EDAM}

Department of Engineering

Harvey Mudd College

Claremont, CA 91711

Phone: (909) 621-8853

Fax: (909) 621-8967

E-mail: Clive_Dym@hmc.edu

Books for review should be submitted to the section editor.

Professor David C. Brown, Book Review Editor

AI EDAM

Department of Computer Science

Fuller Labs 131

100 Institute Road

Worcester Polytechnic Institute

Worcester, MA 01609

Phone: (508) 831-5618

Fax: (508) 831.5776

E-mail: dcb@owl.wpi.edu

Photocopies of typescripts will not be accepted for publication. For refereeing purposes only, good photocopies may be submitted. Upon acceptance of the manuscript the top copy and the original illustrations should be submitted for publication. Authors of accepted manuscripts are urged to submit their final manuscripts on diskette as well as on hard copy, identifying what software was used.

\section{MANUSCRIPT PREPARATION AND STYLE}

Paper should be typed in double spacing throughout, including tables, footnotes, references and legends to tables and fig- ures. One side of the paper, only, should be used and there should be a margin of at least $2.5 \mathrm{~cm}$ all around. The position of tables and figures should be clearly indicated, in sequence, in the text. Tables, footnotes and legends to figures should be typed separately. Where it is essential for clear crossreferencing, particularly in mathematically-orientated material, paragraphs and subparagraphs may be numbered, and the decimal system should be used, i.e. 1.1.1., 1.1.2., etc. A short running title of not more than $\mathbf{4 0}$ characters (including spaces) should be indicated if the full title is longer than this. The name of the laboratory where the work has been carried out should be indicated on the title page and the full posta address for the despatch of proofs and offprints should be in cluded on a separate page. Minor corrections to the manuscript may be typed or neatly printed in ink; retyping is required for significant changes. Numbers should be spelled out when they occur at the beginning of a sentence; use Arabic numerals elsewhere.

\section{MANUSCRIPT ELEMENTS AND ORDER}

Unless there are obvious and compelling reasons for variation (e.g. review articles, short communications), manuscripts should be organized as follows:

Tille page. This is page 1 . The title should be concise, informative, and free of abbreviations, chemical formulae, technical jargon, and esoteric terms. This page should include (a) the article's full title, (b) names and affiliations of all authors, (c) the name, mailing address, and telephone number of the corresponding author, (d) the address for reprint requests if different from that of the corresponding author, (e) a shor title of 50 characters or less, and (f) a list of the number of manuscript pages, number of tables, and number of figures.

Abstract and keywords page. This is page 2 and should in clude (a) the article's full title, (b) an abstract of no more than 300 words, and (c) up to 5 keywords or phrases that reflect the content and major thrust of the article. The abstract should give a succinct account of the objective, methods, results, and significance of the subject matter.

Introduction. This section begins on page 3 and should clearly state the objective of the research in the context of previous work bearing directly on the subject. An extensive review of the literature is not usually appropriate.

Citations in text. Customary abbreviations will be accepted and the authors are recommended to employ Système Internationale (SI/metric) units. Special and unusual symbol should be clearly identified, especially if handwritten. Spell out acronyms at first use, but use only acronyms thereafter. All equipment supplies and products stated in the article should have the manufacturer name and location identified at first mention.

Tables. Tables should be numbered consecutively with Arabic numerals and each should be typed double-spaced on a separate sheet. All tables are to be grouped together after the references. A short explanatory title and column headings should make the table intelligible without reference to the text. All tables must be cited and their approximate positions indicated in the text.

Figures and legends. The number of figures should be the minimum necessary to make the essential points of the paper Figures should be supplied no larger than $8 \times 10^{*}$ (approx $200 \times 250 \mathrm{~mm}$ ) and must be camera-ready. Photographs will be accepted only if the information cannot be presented easily in any other form. Explanation and keys should, as far as possible, be placed in the legends. Photographs for halftone reproduction must be on white glossy paper. Figures should be composed to occupy a single column $(8.3 \mathrm{~cm})$ or two columns $(17 \mathrm{~cm})$ after reduction. Diagrams and illustrations mus have a professional appearance and be typed or drawn with sharp, black lettering to permit reduction. To assure legibility, letters, numbers, and symbols on figures should have a minimum height of $1 \mathrm{~mm}$ when reduced.

Artwork should normally be in black and white; if authors have color figures, the publisher will provide a price quotation for the additional production costs. All figures must be identified on the back with the short title of the paper, figure number, and figure orientation (top or bottom). Prefer ably, figures should be mounted on heavy sheets of the same size as the manuscript. Four complete sets of figures should be carefully packaged in protective envelopes, one to accompany each copy of the manuscript. Each figure must be cited and its approximate position clearly indicted within the text.

Figures must be numbered consecutively with Arabic numerals and be accompanied by a descriptive caption typed double-spaced on a separate sheet. The captions, collected at the end of the manuscript, should concisely describe the fig ure and identify any symbols and/or calibration bars.

References. Entries should be listed alphabetically by lead author at the end of the paper. All authors' names should be included, followed by the year of publication, the full title of the journal, volume, issue number, and inclusive page numbers. For books, the full title should be given, followed by the editors, volume number (if any), page numbers, publisher and place of publication. Citations in the text should read: Brown and Smith (1973), but (Brown \& Smith, 1973). Where there are more than two authors the citation should read: Brown et al. (1973). The conventional Brown (1973a), Brown (1973b) should be used where more than one paper by the author(s) has appeared in the same year. Brief examples:

Journal or Magazine article

Schank, R.C. (1991). Where's the AI? AI Magazine 12(4), 38-49.

Segre, M.A. (1991). Learning how to plan. Robotics and Autonomous Syst. 8(1-2), 93-111.

Book

Dym, C.L. (1994) Engineering design: A synthesis of views. Cambridge University Press, New York.

Chapter in an edited book

Quinlan, J.R. (1983). Learning efficient classification procedures and their application to chess end games. In $\mathrm{Ma}$ chine Learning: An Artificial Intelligence Approach, (Carbonell, J.G., et al., Eds.), Vol. 1, pp. 463-482. Morgan Kaufmann, Los Altos, California.

\section{Proceedings}

Craw, S., \& Sleeman, D. (1990). Automating the refinement of knowledge based systems. Proc. Ninth Europ. AI Conf., 167-172.

\section{Proceedings with publisher identified}

Mittal, S. \& Frayman, F. (1989). Towards a generic model of configuration tasks. Proc. Eleventh Int. Joint Conf. Artificial Intelligence, pp. 1395-1401. Morgan Kaufmann, Los Altos, California.

The alphabetical list of references begins a new page, and must be typed double-spaced. Each in-text citation must have a corresponding reference and vice versa. List works by different authors who are cited within the same parentheses in chronological order, beginning with the earlier work. Journal titles should not be abbreviated. Only published articles and articles in press should appear in this list. Responsibility for the accuracy of references cited lies with the authors.

Author biographies. Brief author biographies will be printed at the end of each paper; they should not exceed 100 words for each author.

\section{COPYEDITING AND PAGE PROOFS}

The publisher reserves the right to copyedit manuscripts to conform to the style of $A I E D A M$. The corresponding author will receive page proofs for final proofreading. No rewriting of the final accepted manuscript is permitted at the proof stage, and substantial changes may be charged to the authors.

\section{OFFPRINTS}

The corresponding author will receive 50 free article offprints. A form will accompany the page proofs allowing orders for complete copies of the issue and for the purchase of additional offprints. Offprint requirements of all coauthors should be included on this form. Orders received after issue printing will be subject to a $50 \%$ reprint surcharge. 


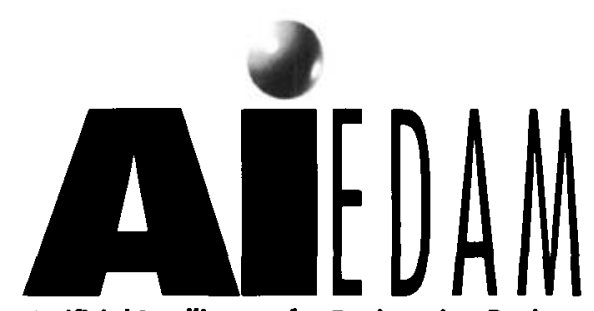

Artificial Intelligence for Engineering Design,

Analysis and Manufacturing

\section{VOLUME 9}

APRIL 1995

NUMBER 2

\section{Special Issue: Concurrent Engineering}

Guest Editorial

William P. Birmingham and Allen Ward

What is Concurrent Engineering?

Comment

Tetsuo Tomiyama

A Japanese View on Concurrent Engineering

Articles

Carolyn C. Hayes and Harold C. Sun

Using a Manufacturing Constraint Network to Identify

Cost-critical Areas of Designs

Susan Finger, Suresh Konda, and Eswaran Subrahmanian

Concurrent Design Happens at the Interfaces. .

Feniosky Peña-Mora, Ram D. Sriram, and Robert Logcher

Conflict Mitigation System for Collaborative Engineering

Michael P. Wellman

A Computational Market Model for Distributed Configuration Design

Daniel Kuokka, Stanley Jefferson, Lee Barford, and Felix Frayman

A Parametric Design Assistant for Concurrent Engineering

Yan Jin, Raymond E. Levitt, Tore R. Christiansen, and John C. Kunz

The Virtual Design Team: Modeling Organizational Behavior

of Concurrent Design Teams

Call For Abstracts

Special Issue on Machine Learning in Design 